\title{
Unusual interleukin-1 and -6 expression in fetal cartilage is associated with placental abnormalities
}

\author{
Franciszek Burdan1, Justyna Szumilo², Agnieszka Korobowicz-Markiewicz' \\ Katarzyna Dyndor ${ }^{1}$, Michal Szumilo ${ }^{4}$, Robert Klepacz ${ }^{2}$
}

\author{
${ }^{1}$ Experimental Teratology Unit of the Human Anatomy Department; Medical University of Lublin, Lublin, \\ Poland \\ ${ }^{2}$ Clinical Pathomorphology Department; Medical University of Lublin, Lublin, Poland \\ ${ }^{3}$ Pediatric Pulmonology and Rheumatology Department, Medical University of Lublin, Lublin, Poland \\ ${ }^{4}$ Applied Pharmacy Department, Medical University of Lublin, Lublin, Poland
}

\begin{abstract}
Unusual expression of interleukin-1alpha, -1beta and -6 was previously found in the epiphyseal cartilage of rat fetuses prenatally exposed to various non-steroidal anti-inflammatory drugs (NSAID, i.e., ibuprofen, piroxicam, tolmetin) and selective cyclooxygenase-2 inhibitor (DFU). The aim of the present study was to evaluate the role of placenta in such phenomenon. Morphology of the organ, thickness of basal and labyrinth layer, immunoexpression of COX isoenzymes were examined, and confronted with maternal biochemical data and fetal developmental parameters. Higher maternal urea level, as well as lower placental weight and labyrinth thickness were found in the group of fetuses who revealed expression of genes coded the selected interleukins, when compared with the xenobiotic-exposed pups without the selected genes expression and untreated control. A significant correlation between placental weight and maternal total protein or urea level was revealed. Histological changes like inflammatory infiltration and calcification were observed sporadically. Location and intensity of COX-1 staining was similar in all cases. However, more intense COX-2 staining for majority of cells of the basal zone and in dispersed giant cells of the labyrinth was found in inflamed organs. It could be concluded that abnormal expression of the selected interleukins is associated with low placental weight and decrease of its thickness, especially labyrinth zone, as well as with high maternal urea level.
\end{abstract}

Key words: NSAID, cyclooxygenase inhibitor, COX-1, COX-2, placental morphology, pregnancy, developmental toxicity

\section{Introduction}

Anatomical and functional differences between fetal and mature immune system explain their various reactivity [1]. Since the fetal $\mathrm{Th}_{1} / \mathrm{Th}_{2}$ cell balance is toward $\mathrm{Th}_{2}$ cells, the immune system synthesizes mainly $\mathrm{Th}_{2}$ cytokines, i.e., IL-4, IL-5, IL-9, IL-10, and TGF- $\beta$ [2-4]. Moreover, the production of pro-inflammatory molecules is decreased. Such adaptive mechanisms are responsible for the tolerance between maternal organism and feto-placental complex, which could be regarded as a semi-allogeneic graft due to high level of paternal antigens [2-5]. In contrast, $\mathrm{Th}_{1} / \mathrm{Th}_{2}$ imbalance

Correspondence: F. Burdan, Experimental Teratology Unit of the Human Anatomy Department, Medical University of Lublin, Jaczewskiego 4 Str., PL-20090 Lublin, Poland; tel.: (+48) 603767649, fax.: (+4881) 5328903,

e-mail: fb3@wp.pl could increase $\mathrm{Th}_{1}$ cytokines synthesis (i.e., IFN- $\gamma$, TNF, IL-1, IL-2, IL-6) that may convert macrophages and NK cells into lectin-activated killers (LAK). The process is highly accelerated due to catalytic capacity of LAKs. Simultaneously, reduction of orexin-2 (OX-2) and increase of pro-thrombinase (fgl2) synthesis by trophoblastic cells occurs. Fgl2 inhibits OX-2 expression itself and converts pro-thrombin into thrombin that activates IL-8 synthesis by endothelial cells and stimulates neutrophils. Both processes are responsible for a vascular thrombosis and assault of the feto-palcental complex, respectively $[3,4]$. In such situation, the prolonged placental blood flow termination leads to embryo/fetal malnutrition that could manifest as intrauterine growth retardation (IUGR), developmental abnormalities or even embryo/fetal dead. All those biochemical and immunological anomalies may be influenced by various infectious, physical and psychological agents, as well as toxicants, including drugs [6]. 
An unexpected expression of genes coded IL- $1 \alpha$, IL-1 $\beta$ and IL-6 was revealed in epiphyseal cartilages in a few rats fetuses in-utero treated with various nonselective (ibuprofen, piroxicam, tolmetin) and selective (DFU*) cyclooxygenase-2 (COX-2) inhibitors [7]. Interestingly, the expression was found only in drugtreated groups, mostly exposed to low and middle doses, which were well-tolerated by both dams and fetuses (Table 1). It seems that due to immaturity of fetal immune system the only source of those cytokines could be the placenta or maternal circulation, and cytokines could cross the impaired placental barrier $[2-4,8]$. The present study was undertaken to evaluate the role of placenta in such phenomenon.

\section{Materials and methods}

Animals and study protocol. The applied methodology was similar to other developmental toxicological studies and was described in details elsewhere [7,9-12]. Succinctly, 280 (20/group) timepregnant Wistar CRL:(WI)WUBR rats were intragastrically treated on gestational day (GD) $8-21$ with various COX inhibitors. Ibuprofen $(8.5,85.0$ and $400.0 \mathrm{mg} / \mathrm{kg} / \mathrm{dose})$ and tolmetin $(8.5,85.0$ and $850.0 \mathrm{mg} / \mathrm{kg} /$ dose) were administered three-times a day, while DFU $(0.2,2.0$ and $20.0 \mathrm{mg} / \mathrm{kg} / \mathrm{dose})$ and piroxicam $(0.3,3.0$ and $30.0 \mathrm{mg} / \mathrm{kg} / \mathrm{dose}$ ) were given once daily. Animals in control groups received the Tween 80 water suspension in volume corresponding to those given $(10 \mathrm{ml} / \mathrm{kg})$ in drug-treated groups (Table 1). On GD 21 dames were sacrificed, their blood was collected, and abdominal organs were delivered. The maternal blood was centrifuged and alanine and aspartate aminotransferase activity, as well as urea and total protein level were determined in the sera. Ovarian corpora lutea, resorption sites, dead or live fetuses were counted. Fetuses were removed from uterus, separated from placenta, and routinely teratologically examined [9]. The weight of fetuses and placentas, and the fetal crown-rump length were checked. Skeletal and internal organ morphology, as well as various histological, immunohistochemical [7] and radiological [12] fetal examinations were also performed.

One well-developed, randomly chosen male fetus and its adjusted placenta was taken from 10 randomly selected litters of each experimental group. However, due to maternal mortality, the final number of evaluated litters in groups exposed to the highest doses of tolmetin and ibuprofen was only 4 and 6 , respectively.

Gene expression. The proximal and distal femoral fetal epiphyses were separated and their RNA was extracted. The expression of genes coded collagen type I and X, COX-1, COX-2, IL- $1 \alpha$, IL-1 $\beta$, IL-6, osteopontin, osteocalcin, TNF- $\alpha$, TNF- $\beta$, L32 and GAPDH was checked using RNase Protection Assay (RPA) with custom multi probe template sets (PharMingen Laboratory; San Diego CA, USA) according to manufacturer directions. The level of mRNA was estimated using computer software TotalLab (BioSystematica, UK), in reference to the mRNA level of the house keeping gene L32 [7].

Immunohistochemistry. All the selected placentas were cut transversally on the level of the umbilical cord adjustment, fixed in $10 \%$ buffered formalin, embedded in paraffin blocks, sectioned at $5 \mu \mathrm{m}$ and routinely stained with hematoxylin and eosin $(\mathrm{H}+\mathrm{E})$. Immuno-
Table 1. Characteristic of litters/fetuses selected to the current study

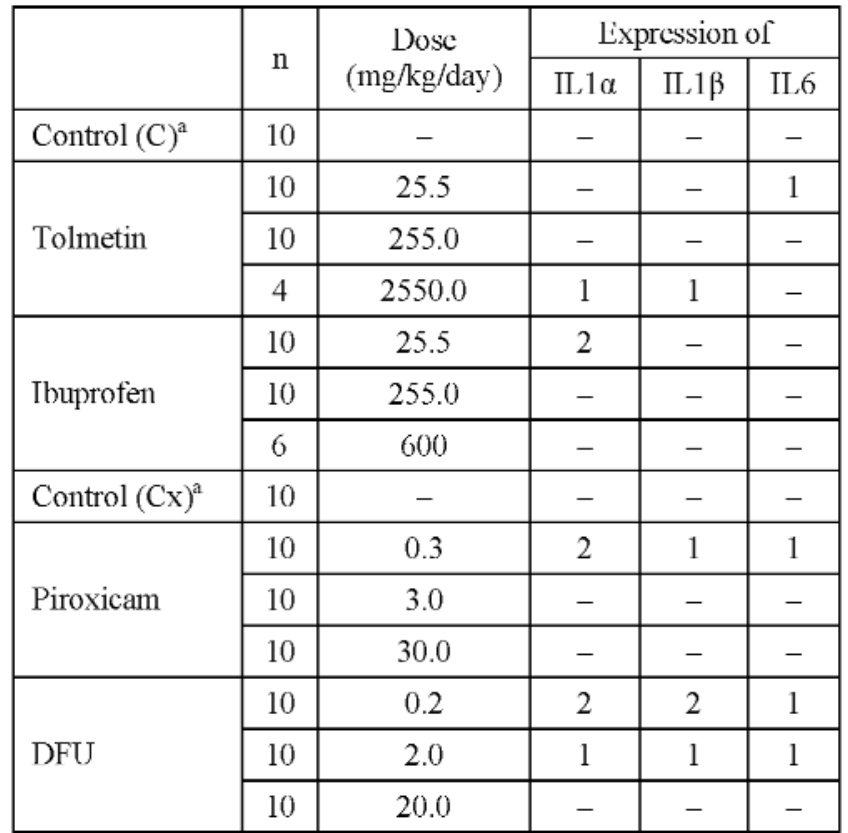

${ }^{\mathrm{a}} \mathrm{C}$ and $\mathrm{Cx}$ groups were pulled into one common control group due to lack of statistical differences in both maternal and fetal parameters

histochemical reactions for both $\mathrm{COX}$ isoforms were performed on the $4 \mu \mathrm{m}$ slides obtained from the paraffin blocks previously used for histological examination. Monoclonal mouse antihuman antibodies against COX-1 and COX-2 (clones 12E12 and 4H12, respectively; Novocastra; Newcastle, UK) and DakoEnvision $^{+\mathrm{TM}} / \mathrm{HRP}$ kit (DakoCytomation, Glostrup, Denmark) were applied. The details of the method were described elsewhere [13]. Slides were evaluated without knowledge of the treatment groups, using light microscope (Olympus BX45; Tokyo, Japan). The thickness of the basal (junctional) zone and the labyrinth of the placenta was measured using the eyepiece micrometer at the objective 10x (Fig. 1). The obtained results were expressed as absolute (in millimeters) and relative values (vs. the whole placental thickness).

Ethical issues. All the evaluated samples and data were collected during the previous study that was designed in accordance with international guidelines for teratological studies [9] and fully approved by the Local Bioethical Committee (\#372/2002).

Statistical analysis. Unlike typical teratological studies, the unit for statistical measurement was the pregnant female, placenta or single, male fetus selected for the genetic and histological evaluation [9]. Homogeneity of distribution was examined using Kolmogorov-Smirnov test. Differences of normal distribution data were analysed by ANOVA and followed by Duncan test. Inhomogeneous distribution data was analysed by Mann-Whitney U test. The nominal scale measures were analyzed by Chi-square test with Yates' correction for independent differences among experimental groups. Spearman rank test was employed to evaluate correlations between various factors. The 0.05 level $(p<0.05)$ of probability was used as the criterion of significance. Data were analyzed using STATISTICA 5.0 on IBM compatible computer. 
Table 2. Selected maternal, fetal and placental parameters in the control and drug-exposed groups according to ILs expression

\begin{tabular}{|c|c|c|c|}
\hline & \multirow{2}{*}{ Control } & \multicolumn{2}{|c|}{ Drug-exposed groups } \\
\hline & & II, absence & II, presence \\
\hline Number of animals/placentas & 20 & 100 & 10 \\
\hline Alanine aminotrans[erase (IU/1) & $60.80 \pm 8.17$ & $66.00 \pm 18.93$ & $59.90 \pm 9.79$ \\
\hline Aspartale aminotransfcrasc (IU/1) & $155.10 \pm 38.81$ & $161.64 \pm 60.02$ & $139.60 \pm 51.24$ \\
\hline Total protcin $(\mathrm{g} / \mathrm{l})$ & $61.66 \pm 6.35$ & $58.39 \pm 5.44$ & $57.63 \pm 6.18$ \\
\hline $\operatorname{Urea}(\mathrm{mmol} / \mathrm{l})$ & $7.09 \pm 0.92$ & $8.27 \pm 0.95^{*}$ & $8.01 \pm 1.23^{* \text {, \# }}$ \\
\hline l'ctal weight $(\mathrm{g})$ & $3.68 \pm 0.14$ & $3.60 \pm 0.18$ & $3.55 \pm 0.11$ \\
\hline l'ctal length (mm) & $37.31 \pm 1.34$ & $35.99 \pm 5.87$ & $36.46 \pm 1.64$ \\
\hline Placental weight (g) & $0.57 \pm 0.62$ & $0.56 \pm 0.06$ & $0.47 \pm 0.04^{*}, \#$ \\
\hline Placental weight/fetal weight (\%) & $15.54 \pm 1.58$ & $15.36 \pm 2.19$ & $13.17 \pm 1.37^{*}$, \# \\
\hline \multicolumn{4}{|l|}{$\Lambda$ bsolute thickness $(\mathrm{mm})$} \\
\hline placental & $2.97 \pm 3.16$ & $2.96 \pm 0.41$ & $2.62 \pm 0.35^{*, 4}$ \\
\hline - basal zone & $0.72 \pm 0.87$ & $0.70 \pm 0.13$ & $0.71 \pm 0.10$ \\
\hline - labyrinth & $2.25 \pm 0.27$ & $2.26 \pm 0.34$ & $1.91 \pm 0.25^{*, \#}$ \\
\hline Relative thickness of labytinth (\%) & $75.49 \pm 2.37$ & $76.16 \pm 3.59$ & $72.98 \pm 1.25^{*}$ \\
\hline
\end{tabular}

${ }^{*} \mathrm{p}<0.05$ vs. control; ${ }^{*} \mathrm{p}<0.05$ vs. IL absence

Table 3. The fetal incidence in corresponding to normal ${ }^{\text {a }}(95 \mathrm{CI})$ and abnormal $(<95$ and $>95 \mathrm{CI})$ value of selected maternal and placental parameters in drug-exposed groups according to ILs expression.

\begin{tabular}{|l|l|c|c|c|}
\hline & & $<95 \mathrm{CI}$ & $95 \mathrm{CI}$ & $>95 \mathrm{CI}$ \\
\hline \multirow{2}{*}{$\begin{array}{l}\text { Urea } \\
(6.66-7.72 \mathrm{mmol} / 1)^{\mathrm{a}}\end{array}$} & II, absence & $4 / 100$ & $12 / 100$ & $84 / 100$ \\
\cline { 2 - 6 } & IL presence & $2 / 10$ & $1 / 10$ & $7 / 10$ \\
\hline \multirow{2}{*}{$\begin{array}{l}\text { Placental weight } \\
(0.54-0.60 \mathrm{~g})^{\mathrm{a}}\end{array}$} & IL absence & $33 / 100$ & $23 / 100$ & $44 / 100$ \\
\cline { 2 - 6 } & IL presence & $9 / 10$ & $1 / 10$ & $0 / 10$ \\
\hline $\begin{array}{l}\text { Relative labyrinth thickness } \\
(74.39-76.60 \%)^{\mathrm{a}}\end{array}$ & IL absence & $30 / 100$ & $25 / 100$ & $45 / 100$ \\
\cline { 2 - 6 } & IL presence & $9 / 10$ & $1 / 10$ & $0 / 10$ \\
\hline
\end{tabular}

athe normal value was calculated as $95 \mathrm{CI}$ in the common control group

\section{Results}

For the final statistical analysis data from 130 dams, corresponding fetuses and placentas (including 20 from control groups) was taken.

The urea level was significantly lower in both drugexposed groups when compare with the control group (Table 2). However, it was higher in the group of dams whose pups exhibited expression of interleukins in the epiphyseal homogenates. Lack of statistical differences was found for other biochemical parameters, as well as both fetal developmental parameters, i.e., the fetal weight and the crown-rump length. Placental weight was significantly lower in the group of fetuses who revealed expression of genes coded selected interleukins in cartilages then in other two groups (Table 2).

In the group with expression of interleukin genes most of the fetuses were obtained from mothers with higher serum urea level, as well as with low placental weight and thickness of the labyrinth (Table 3). When maternal and feto-placental parameters were simultaneously evaluated, in the group without interleukin genes expression a statistically significant correlation between placental weight and urea or total protein level was revealed (Fig. 2).

The evaluated placentas showed morphology typical of hemochorial - chorioallantoic ones, with well developed basal zone and labyrinth. The basal zone contained three main types of cells, i.e., undifferentiated, glycogen and giant trophoblasts cells, as well as maternal vascular channels. Whereas labyrinth was composed of dense network of lacunas filled with maternal blood formed by the septa consisted of three layers of trophoblasts and vascular fetal mesenchyma (Fig. 1, 3). In majority of cases mild inflammatory infiltration composed of neutrophils and degenerated/necrotic cells were found in the decidua basalis and nearby basal zone of the placenta. However, in all pla- 
centas from group exposed to the highest dose of tolmetin, six from group treated with middle dose of piroxicam, four from control and one from group received middle dose of DFU, the infiltration was severe and observed both on the fetal aspect of the pla-

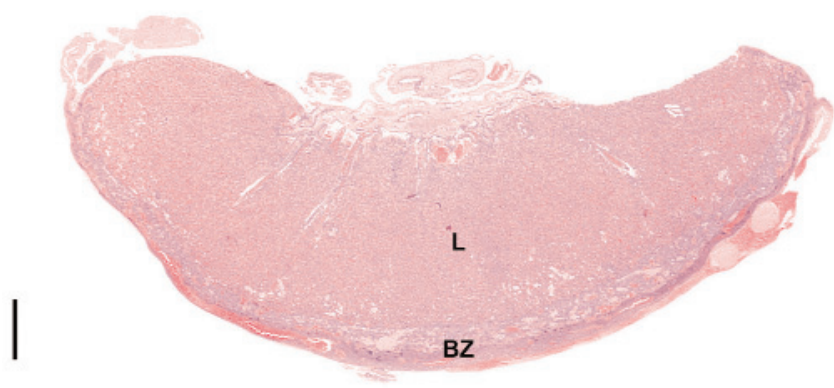

Fig. 1. The transversal section of the rat placenta; $\mathrm{BZ}$ - basal zone, $\mathrm{L}$ - labyrinth (piroxicam $3.0 \mathrm{mg} / \mathrm{kg} / \mathrm{d} \mathrm{H}+\mathrm{E}$; bar $-1 \mathrm{~mm}$ ). centa and deeply within both zones of the organ (Fig. 3A). Small foci of calcification were noted in the maternal-fetal interface in three pups exposed to middle dose of piroxicam (2) and highest dose of tolmetin (1) (Fig. 3B).

Unlike unaffected thickness of the basal zone, the transversal diameter of the whole placenta and the labyrinth was significantly lower in the group of rats with expression of genes coded selected interleukins (Table 2).

The distribution and intensity of imunostaining for COX-1 in placentas was similar in all groups. Except for erythrocytes, strong cytoplasmic reaction was seen in virtually all cells (Fig. 4A, B). Immunostaining for COX-2 was usually very weak and confined mostly to trophoblasts cells (layer 1) and endothelial cells of the labyrinth (Fig. 4C). However in placentas infiltrated by neutrophils, a strong nuclear staining was also revealed in majority of cells of the basal zone and in dispersed giant cells of the labyrinth (Fig. 4D).
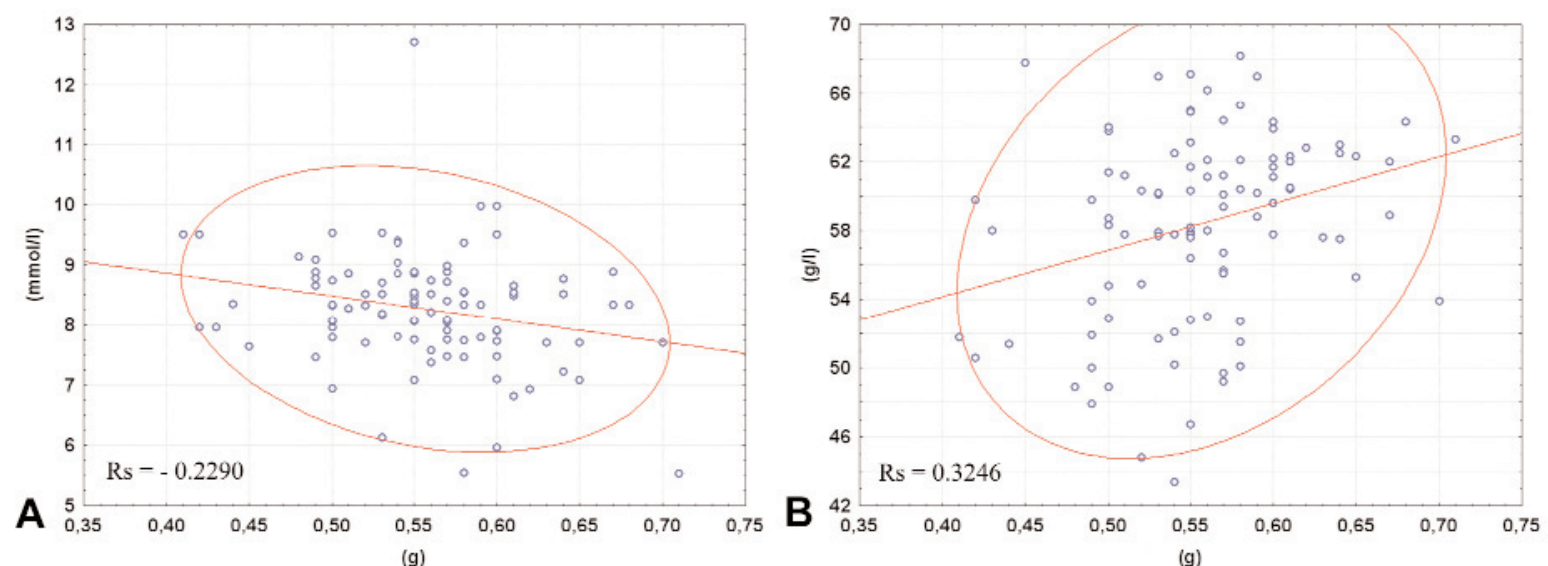

Fig. 2. Correlation between placental weight and maternal urea (A) or total protein (B) level in rat fetuses prenatally exposed to cyclooxygenase inhibitors without expression of IL-1 $\alpha$, IL-1 $\beta$ and IL-6. Rs - Spearman rank R.
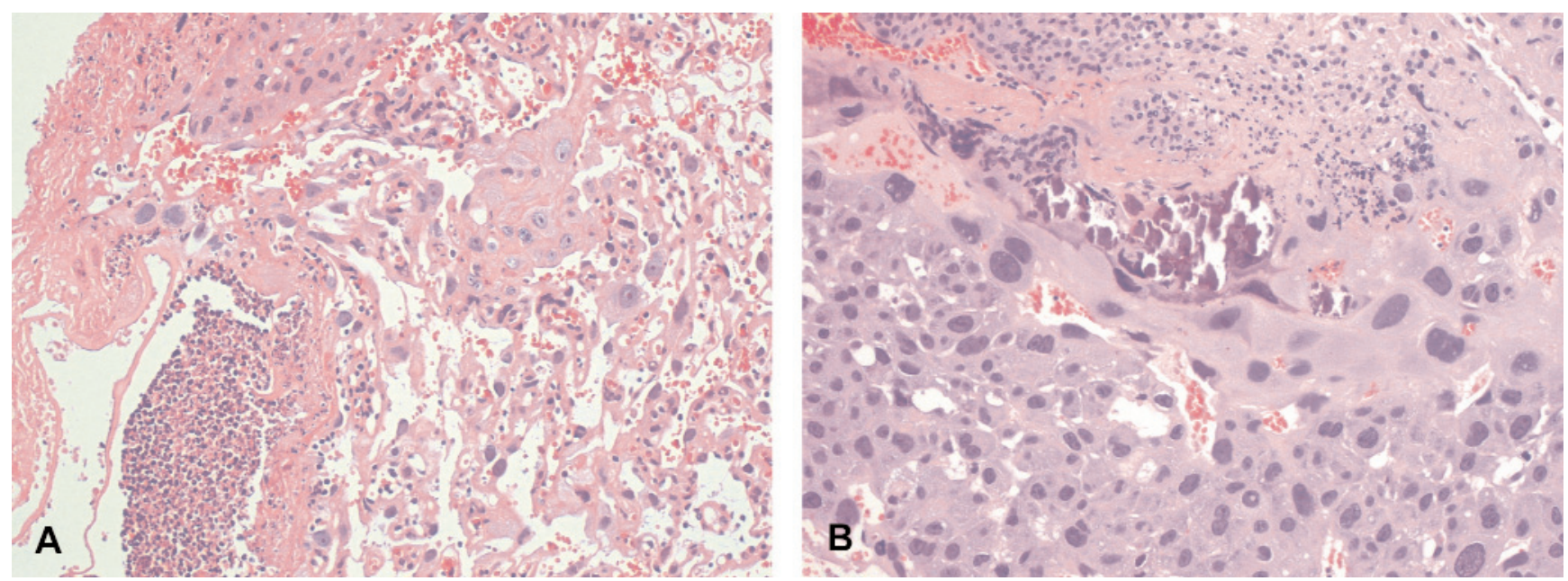

Fig. 3. Neutrophils on the fetal aspect of the placenta $(\mathbf{A})$ and calcification in the basal zone of the placenta $(\mathbf{B})(\mathrm{H}+\mathrm{E} ; \mathrm{A}-\mathrm{DFU} 2 \mathrm{mg} / \mathrm{kg} / \mathrm{d}$, objective 10×; B - tolmetin $2550 \mathrm{mg} / \mathrm{kg} / \mathrm{d}$, objective $20 \times$ ). 

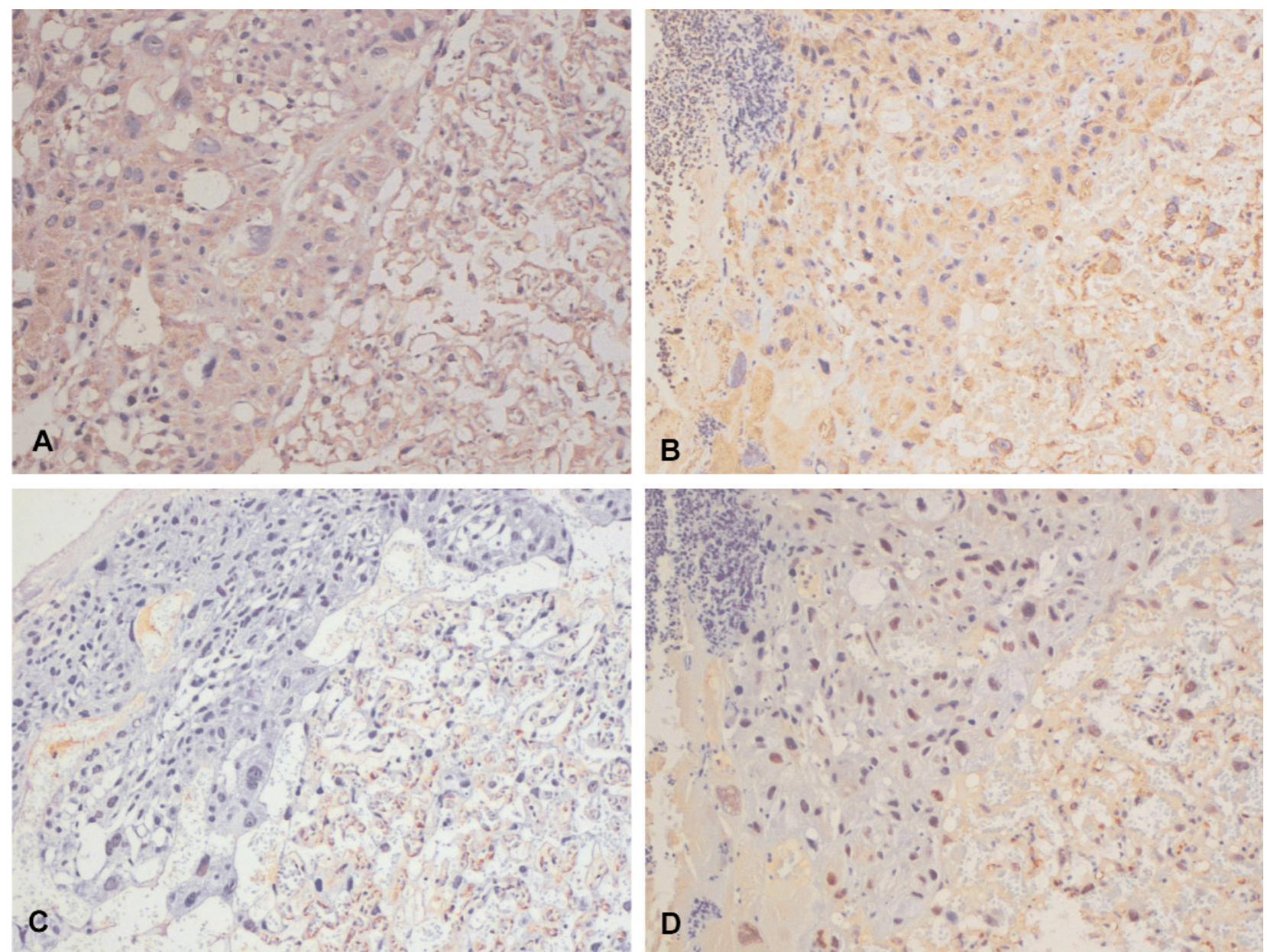

Fig. 4. Immunohistochemical reaction for COX-1 (A, B) and COX-2 (C, D) in normal placenta $(\mathbf{A}, \mathbf{C})$ and infiltrated by neutrophils $(\mathbf{B}$, D) (A, C - ibuprofen $25.5 \mathrm{mg} / \mathrm{kg} / \mathrm{d}$; B, D - tolmetin $2550.0 \mathrm{mg} / \mathrm{kg} / \mathrm{d}$; DakoEnvision ${ }^{\mathrm{TM}+} / \mathrm{HRP}$, objective 10x).

\section{Discussion}

The obtained results indicated that unusual expression of $I L-1 \alpha, I L-1 \beta$ and $I L-6$ was seen in fetuses delivered by mothers with an abnormal urea level. The group was also characterized by a low placental weight and thinner labyrinth. Histological abnormalities, mostly dense inflammatory infiltration and/or sparse foci of calcifications were revealed occasionally in all three evaluated groups, including common control one. However, in animals exposed to the highest dose of tolmetin, placental changes were found in all the examined litters. On the other hand, placental histological abnormalities were revealed only in four out of 10 organs obtained from fetuses with a positive interleukins expression, as well as in 12/100 organs of pups without genetic abnormalities and exposed to the examined COX inhibitors. A lower frequency $(4 / 20)$ was found in the common control group. Nevertheless, it has to be stated that mild inflammation and focal necrosis of placenta are physiological findings that could be observed also in healthy organs from GD 17 until partum [14]. Lack of any serious abnormalities typical for well-known placental toxicants, like methyl parathion was found [15]. The inflammatory process explains the strong immunoexpression of the inducible COX isoform [16,17], while more intensive staining for both, COX-1 and COX-2 of the basal zone in the late gestation is physiological [18].

Interestingly, the previous results suggested that among the whole group of animals exposed in-utero to COX inhibitors, the abnormal urea and/or total protein level was associated with increase incident of postimplantation loss and IUGR, low placental weight, increase of skeletal developmental malformations and variations [19], as well as decrease of vertebrae mineralization [12]. Such data was also partially proved for domestic animals fed with diet rich with degradable proteins that generate a high level of urea in maternal blood $[20,21]$. However, a maternal toxicity can not be taken into consideration as a leading mechanism that explains interleukin expression, since the phenomenon was observed mostly in fetuses obtained from mothers without gross and histological signs of adverse effects of the examined xenobiotics $[10,11]$.

Although, damage of placental barrier was not proved on histological level, such mechanism is the only one that 
could explain positive $I L-1 \alpha, I L-1 \beta$ and $I L-6$ expression in fetal cartilages. Since well-vascularised labyrinth was the only affected part of the placenta, the mechanism may be related to homodynamic changes in arteries that supply the organ. Due to high COX activity in endothelial cells and thrombocytes, the examined drugs could affect prostacyklin (PGI) and thromboxan (TXA2) synthesis, respectively. Secondary to PGI/TXA2 modulation, the local haemostatic changes occur, and temporary or permanent vascular occlusion could be generated [16,17,22]. The ischemia-reperfusion (I/R) injury itself is a pivotal mechanism of IUGR and pre-eclampsia [22]. It could also promote pathological changes that generate maternal-fetal blood shunt $[6,22]$. Yamazaki et al. [23] reported that I/R injury increase the placental COX-2 and EP3 receptor expression that may induce IUGR through the prostaglandin E2 (PGE2) stimulation. However, according to the authors the fetal effect was time-dependent since significant changes in fetal weight were revealed not earlier than 5 day after the uterinal artery was closed. Furthermore, the thrombo-embolic episodes are welldocumented complications of some of the selective COX-2 inhibitors therapy and were the main reason for their withdrawn from the market. A new data suggests that similar adverse effects could be observed in patients taking nonselective compounds, as well [24,25]. It should be also emphasized that COX inhibitors decrease synthesis of PGE2, one of the strongest vasoconstrictor, which stimulates mainly EP3 receptors $[16,17]$. Because there is a dualistic influence of the examined drugs on haemostase, other studies are needed to find the main mechanism of placental injury. However, without maternal blood and placental interleukin levels, as well as local haemostatic examination such divagations are pure theoretical, since the cytokine source is unknown. An unusual stimulation of the fetal immune system with secondary activation of $\mathrm{Th}_{1}$ cytokines seems even less likely, especially since histological skeletal changes were observed occasionally in the examined rat population [7]. On the other hand, most of the currently studied fetuses showed a positive expression of TNF [7], that is $\mathrm{Th}_{1}$ cytokine promoting the immune response to infection [2,26,27]. Nevertheless, since TNF plays a cruciate role in various processes such as organogenesis and initiation of partum of the placenta [28], its expression in fetal tissues is physiological through the mid and late pregnancy [27]. Its concentration could be increased by various pathological factors that also stimulate other $\mathrm{Th}_{1}$ cytokines, like IL-1 and -6 , which may damage fetal and mature organs [27,29-31]. Such mechanism was experimentally confirmed by Bell et al. [2]. The authors injected lipopolysaccharide into the uterine cervix of pregnant rats and found an increase of TNF concentration in the placenta and the fetal brain, while the level of IL-1 was increased only in the placenta and INF- $\gamma$ exclusively in the brain. Due to the fact that all those factors are respon- sible for the neuronal degeneration [26,28], it is postulated that $\mathrm{Th}_{1}$ cytokines may induce congenital abnormalities of the central nervous system. Since TNF and other cytokines do not cross the healthy placenta [32], the infected organ has to be the only source of the $\mathrm{Th}_{1}$ cytokines, especially TNF and IL-6. The role of intrauterine infection in promotion of the brain congenital abnormalities has been already proved in experimental animal models $[33,34]$, but in none of the study placental morphology was evaluated. However, Silen et al. [8] revealed necrosis in both labyrinth and basal zones, as well as in some organs of fetuses delivered by dams interperitonally injected with native IL-1 $\alpha$ and TNF.

It should be also noted that low placental weight is one of the most commonly affected developmental parameter, observed in various teratological studies $[6,9]$. Dose-dependent, however insignificant differences were revealed in groups treated with COX inhibitors in the currently examined rat population $[10,11]$ and in some previous studies $[6,9,35]$. So-called placental toxicity is a major factor explaining developmental complications of arsenic, cadmium, chloroform, enalapril, trypan blue and methyl parathion [6]. All the compounds cause placental necrosis and enzymatic changes that may compromise placental function. Affecting gas exchange, nutrition uptake and abnormal hormonal synthesis were also revealed during exposition to other chemicals, but none of the studies evaluated $\mathrm{Th}_{1}$ cytokines in the fetal tissues $[3,6,9,15]$.

Lack of the differences in fetal weight and length may be caused by the method used to select the pups for genetic and histological examinations. Since only one well-developed fetus from the litter without any signs of external malformations and IUGR was evaluated, the obtained results could be false negative and other studies have to be taken to completely explain this phenomenon.

On the basis of obtained results, it could be concluded that abnormal expression of selected interleukins is associated with low placental weight, decrease of placental thickness, particularly labyrinth, as well as with high urea level in maternal blood. Other studies, especially multi-generation ones, are required to explain clinical implications of this phenomenon [9,36,37]. An additional evaluation of specific placental hormones and proteins $[30,38]$ will be also desirable for the future human risk assessment $[9,30,36,37,39,40]$. Histological placental examination seems to be important scientific procedure, especially in cases the organ weight and fetal abnormalities are revealed. Presently, according to international principles for developmental toxicological evaluations it is only an accessory facultative test [9].

\section{References}

[1] Holsapple MP, West LJ, Landreth KS. Species comparison of anatomical and functional immune system development. Birth Defects Res B Dev Reprod Toxicol. 2003;68:321-334. 
[2] Bell MJ, Hallenbeck JM, Gallo V. Determining the fetal inflammatory response in an experimental model of intrauterine inflammation in rats. Pediatr Res. 2004;56:541-546.

[3] Thellin O, Heinen E. Pregnancy and the immune system: between tolerance and rejection. Toxicology. 2003;185:179-184.

[ 4] Van Loveren H, Vos J, Putman E, Piersma A. Immunotoxicological consequences of perinatal chemical exposures: a plea for inclusion of immune parameters in reproduction studies. Toxicology. 2003;185:185-191.

[5] Koch CA, Platt JL. T cell recognition and immunity in the fetus and mother. Cell Immunol. 2007;248:12-17.

[6] Lewis SH, Perrin E. Pathology of the Placenta. 2 ed. New York: Churchill Livingstone; 1999.

[ 7] Burdan F, Szumilo J, Marzec B, Klepacz R, Dudka J. Skeletal developmental effects of selective and nonselective cyclooxygenase- 2 inhibitors administered through organogenesis and fetogenesis in Wistar CRL:(WI)WUBR rats. Toxicology. 2005;216:204-223.

[ 8] Silen ML, Firpo A, Morgello S, Lowry SF, Francus T. Interleukin-1 alpha and tumor necrosis factor alpha cause placental injury in the rat. Am J Pathol. 1989;135:239-244.

[ 9] Christian MS. Test methods for assessing female reproductive and developmental toxicology. In: Hayes AW, ed Principles and Method of Toxicology. 4th ed, Philadelphia: Taylor \& Francis; 2001:1301-1381.

[10] Burdan F. Comparison of developmental toxicity of selective and non-selective cyclooxygenase-2 inhibitors in CRL:(WI)WUBR Wistar rats--DFU and piroxicam study. Toxicology. 2005;211:12-25.

[11] Burdan F. Developmental toxicity evaluation of ibuprofen and tolmetin administered in triple daily doses to Wistar CRL:(WI)WUBR rats. Birth Defects Res B Dev Reprod Toxicol. 2004;71:321-330.

[12] Burdan F, Rozylo-Kalinowska I, Szumilo J, Dudka J, Klepacz R. Cyclooxygenase inhibitors affect bone mineralization in rat fetuses. Cells Tissues Organs. 2008;187:221-232.

[13] Burdan F, Szumiło J, Gajjar B, et al. Immunoexpression of constitutive and inducible cyclo-oxygenase isoforms in the rat foetal and maternal digestive tract. Folia Morphol. 2008;67: 24-31.

[14] de Rijk EP, van Esch E, Flik G. Pregnancy dating in the rat: placental morphology and maternal blood parameters. Toxicol Pathol. 2002;30:271-282.

[15] Levario-Carrillo M, Olave ME, Corral DC, Alderete JG, Gagioti SM, Bevilacqua E. Placental morphology of rats prenatally exposed to methyl parathion. Exp Toxicol Pathol. 2004;55:489-496.

[16] Burdan F, Chałas A, Szumiło J. Cyclooxygenase and prostanoids - biological implications. Postepy Hig Med Dosw. 2006;60:129-141.

[17] McGiff JC. Vascular prostaglandin synthesis: the early days. Pharmacol Rep. 2006;58 (suppl 1):47-51.

[18] Xu Y, Knipp GT, Cook TJ. Expression of cyclooxygenase isoforms in developing rat placenta, human term placenta, and BeWo human trophoblast model. Mol Pharm. 2005;2:481490.

[19] Burdan F, Szumilo J, Klepacz R. Maternal toxicity of nonsteroidal anti-inflammatory drugs as an important factor affecting prenatal development. Reprod Toxicol. 2009;28: 239-44.

[20] Campanile G, Neglia G, Di Palo R, et al. Relationship of body condition score and blood urea and ammonia to pregnancy in Italian Mediterranean buffaloes. Reprod Nutr Dev. 2006;46: 57-62.

[21] Rhoads ML, Rhoads RP, Gilbert RO, Toole R, Butler WR. Detrimental effects of high plasma urea nitrogen levels on viability of embryos from lactating dairy cows. Anim Reprod Sci. 2006;91:1-10.
[22] Abran D, Dumont I, Hardy P, et al. Characterization and regulation of prostaglandin E2 receptor and receptor-coupled functions in the choroidal vasculature of the pig during development. Circ Res. 1997;80:463-472.

[23] Yamazaki K, Endo T, Kitajima Y, et al. Elevation of both cyclooxygenase-2 and prostaglandin E2 receptor EP3 expressions in rat placenta after uterine artery ischemia-reperfusion. Placenta. 2006;27:395-401.

[24] Głuszko P, Bielińska A. Non-steroidal anti-inflammatory drugs and the risk of cardiovascular diseases: are we going to see the revival of cyclooxygenase-2 selective inhibitors? Pol Arch Med Wewn. 2009;119:231-235.

[25] Roumie CL, Mitchel EF Jr, Kaltenbach L, Arbogast PG, Gideon P, Griffin MR. Nonaspirin NSAIDs, cyclooxygenase 2 inhibitors, and the risk for stroke. Stroke. 2008;39:20372045.

[26] Cammer W. Effects of TNFalpha on immature and mature oligodendrocytes and their progenitors in vitro. Brain Res. 2000;864:213-219.

[27] Korobowicz A. Biology of tumor necrosis factor type alpha (TNF-alpha). Pol Merkur Lekarski. 2006;21:358-361.

[28] Arntzen KJ, Kjř llesdal AM, Halgunset J, Vatten L, Austgulen R. TNF, IL-1, IL-6, IL-8 and soluble TNF receptors in relation to chorioamnionitis and premature labor. J Perinat Med. 1998;26:17-26.

[29] Kamiński KA, Oledzka E, Białobrzewska K, Kozuch M, Musiał WJ, Winnicka MM. The effects of moderate physical exercise on cardiac hypertrophy in interleukin 6 deficient mice. Adv Med Sci. 2007;52:164-168.

[30] Morisset J. Hormonal control of pancreatic growth during fetal, neonatal and adult life. Adv Med Sci. 2008;53:99-118.

[31] Pietrzak A, Zalewska A, Chodorowska G, et al. Genes and structure of selected cytokines involved in pathogenesis of psoriasis. Folia Histochem Cytobiol. 2008;46:11-21.

[32] Carbó N, López-Soriano FJ, Argilés JM. Tumour necrosis factor-alpha does not cross the rat placenta. Cancer Lett. 1998;128:101-104.

[33] Debillon T, Gras-Leguen C, Vérielle V, et al. Intrauterine infection induces programmed cell death in rabbit periventricular white matter. Pediatr Res. 2000;47:736-742.

[34] Yoon BH, Kim CJ, Romero R, et al. Experimentally induced intrauterine infection causes fetal brain white matter lesions in rabbits. Am J Obstet Gynecol. 1997;177:797-802.

[35] Romo A, Carceller R, Tobajas J. Intrauterine growth retardation (IUGR): epidemiology and etiology. Pediatr Endocrinol Rev. 2009;6 (suppl 3):332-336.

[36] Beekhuijzen M, Zmarowski A, Emmen H, Frieling W. To mate or not to mate: a retrospective analysis of two-generation studies for evaluation of criteria to trigger additional mating in the extended one-generation design. Reprod Toxicol. 2009;28:203-208.

[37] Dang ZC, Rorije E, Esch TH, Muller A, Hakkert BC, Piersma AH. Retrospective analysis of relative parameter sensitivity in multi-generation reproductive toxicity studies. Reprod Toxicol. 2009;28:196-202.

[38] Paszkiewicz-Gadek A, Porowska H, Sredzińska K. Expression of MUC1 mucin in full-term pregnancy human placenta. Adv Med Sci. 2008;53:54-58.

[39] Barrow PC. Reproductive toxicity testing for pharmaceuticals under ICH. Reprod Toxicol. 2009;28:172-179.

[40] Gebel T, Lechtenberg-Auffarth E, Guhe C. About hazard and risk assessment: regulatory approaches in assessing safety in the European Union chemicals legislation. Reprod Toxicol. 2009;28:188-195. 